\section{(a) RMA}

VI Jornadas

Arqueológicas Cuyanas

\section{Una aproximación a las trayectorias estilísticas cerámicas del valle de Guandacol (Provincia de La Rioja): continuidades y rupturas entre los siglos XIII y XVIII}

\author{
An approximation to the technological trajectories \\ of the Guandacol valley ceramics (La Rioja Province): \\ continuities and ruptures between the $13^{\text {th }}$ and $18^{\text {th }}$
}

centuries

\begin{abstract}
*Departamento de Geología, Facultad de Ciencias Físico, Matemáticas y Naturales (UNSan Luis), Instituto de Arqueología y Etnología, Facultad de Filosofía y Letras (UNCuyo), Mendoza, Argentina. E-mail: sebacarosio@yahoo.com.ar ** INCIHUSA-CONICET, Instituto de Arqueología y Etnología, Facultad de Filosofía y Letras (UNCuyo), Mendoza, Argentina. E-mail: liniesta@mendoza-conicet.gob.ar
\end{abstract}

\begin{abstract}
Resumen
Presentamos una síntesis de los resultados de nuestros estudios sobre las manifestaciones estilísticas cerámicas del valle de Guandacol (La Rioja). Abordamos la alfarería desde una perspectiva metodológica que involucra análisis macroscópicos, submacroscópicos y microscópicos, con el objetivo de registrar los atributos relacionados con la cadena de producción. A partir del análisis de las diferentes técnicas implementadas en el tratamiento de materias primas, en el levantado de las piezas y sus formas, en la decoración y en las cocciones, reconocemos similitudes y diferencias entre los diversos Estilos identificados. Por ello indagamos en las trayectorias de continuidad y ruptura en las prácticas de manufactura entre los siglos XIII y XVIII.
\end{abstract}

Palabras clave: Estilos cerámicos; valle de Guandacol; cambios y continuidades tecnológicas; siglos XIII-XVIII.

\begin{abstract}
We present the results of our studies of the stylistic manifestations ceramics that show the different archaeological sites in the Guandacol valley (La Rioja). We address the pottery from a methodological perspective, which involves submacroscopics, macroscopic and microscopic analysis, with the objective of record the attributes related to the chain of production. From the appreciation of the different techniques implemented in the treatment of raw materials, in the vessels shaping and its forms, in the decoration and in the cooking, we recognize similarities and differences between the various styles, and search the continuity and rupture trajectories in the manufacturing practices between the $13^{\text {th }}$ and $18^{\text {th }}$ centuries.
\end{abstract}

Keywords: ceramic styles; Guandacol valley; technology changes and continuities; $13^{\text {th }}$ and $18^{\text {th }}$ centuries.

Consideramos a la cerámica como parte de la cultura material de un grupo social, construida desde las técnicas de manufactura y desde los usos y concepciones que la sociedad realiza sobre los mismos. De esta manera, la elaboración no solo abarca productores, materias primas, organización espacial y consumidores, sino también conocimientos tecnológicos sobre las acciones y gestos para la transformación de los materiales y el producto final (Rice 1987; Lemonnier 1992).

Bajo esta perspectiva nos enfocamos en analizar los Estilos alfareros del valle de Guandacol (departamento Felipe Varela, oeste de La Rioja) (Figura 1), los que entendemos como la suma de regularidades de atributos tecnológicos, morfológicos, decorativos y pictóricos de una cadena operativa (Cobas y Prieto 1998). De esta manera, a partir del reconocimiento de similitudes y diferencias, indagamos sobre las trayectorias de cambios y continuidades en las prácticas de manufactura entre los siglos XIII y XVIII.

\section{Antecedentes cerámicos}

Los estudios sobre la cerámica en Guandacol son escasos, aunque significativos. Las labores de De la Fuente (1973) y de Callegari y Gonaldi (2007-2008) se concentraron en la Tambería, el sitio más extenso del valle y lo señalaron, a partir del registro cerámico, arquitectura y fechados, como parte de la "cultura Sanagasta/ Angualasto" 


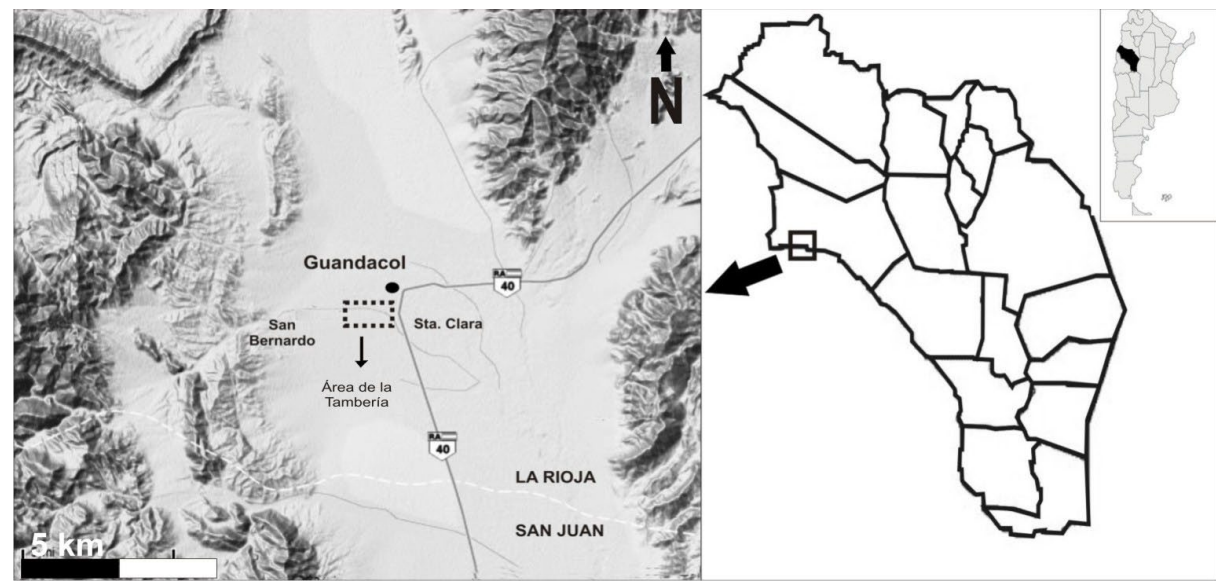

Figura 1. Área geográfica del valle de Guandacol.

Figure 1. Geographical of the Guandacol valley

\section{Materiales y métodos}

Trabajamos con la totalidad de los fragmentos cerámicos recuperados en los trabajos, fundamentalmente, de prospecciones sistemáticas $(\mathrm{N}=10074)$. La mayor parte de la concentración de tiestos se halla en los ambientes de

(Boman 1927-1932) en el periodo Agroalfarero Tardío (ca. 1200-1470 AD). Asimismo, reconocieron alfarerías vinculadas a la dominación Inca (ca. 1470-1535 AD), al Agroalfarero Medio y a la fase transicional del Formativo a los Desarrollos Regionales (ca. 600-1200 AD). En nuestras investigaciones recientes reconocimos varios Componentes Morfoestilísticos. Estos agrupamientos se basan en idénticos rasgos tecnonológicos y decorativos, los que fueron asignados en su amplia mayoría a los Estilos del periodo Tardío y en menor medida al periodo Inca y Formativo Medio (Bárcena 2010; Carosio et al. 2011).

Los Componentes del Estilo Sanagasta/Angualasto desde una perspectiva macroscópica y submacroscópica, poseen una relativa uniformidad tecnológica en casi todas las fases de producción. Asimismo, se estableció una correspondencia química entre las cerámicas y arcillas recuperadas en la cercanía de la Tambería (Carosio et al. 2012). La información, en combinación con el resto de datos arqueológicos, permitió establecer la idea de la existencia de una "tradición alfarera" durante el Tardío regional, en el marco de un modelo de producción local basado en la transmisión de conocimientos y condicionado por pautas socioculturales y económicas. No obstante, existen algunas modificaciones en las prácticas de manufactura a lo largo del periodo (Carosio 2015).

Estos conjuntos del Tardío mostraron, a su vez, ciertas similitudes composicionales con las cerámicas identificadas de los Estilos Aguada, Sanagasta Pasta Compacta e Inca Local, aunque con algunas diferencias (Carosio et al. 2012).

A partir de los trabajos de relevamiento y prospección en el área de Precordillera y en el fondo de valle, se reconocieron alfarerías asimilables a las de la Tambería, pero también otras hasta entonces no identificadas. Tecnológicamente los nuevos Componentes, agrupados en un Estilo que denominamos Santa Clara, reflejan similitudes y diferencias entre sí y con el resto. Estas guardan la particularidad de haber sido asignadas los siglos XVII y XVIII, según TL (Iniesta y Bárcena 2014). Sin embargo, aclaramos que la complejidad cronológica para el oeste riojano ha dificultado la contextualización temporal del registro en general (Callegari y Gonaldi 2006). barreales ( $\mathrm{N}=8774)$, sitios Tambería, Santa Clara y San Bernardo. En el fondo de valle se recuperó material sobre las márgenes del río Guandacol/ La Troya $(\mathrm{N}=1216)$ y en el río De La Vuelta $(\mathrm{N}=16)$. Por último, en la Precordillera se obtuvieron 65 tiestos. El registro fue asignado, de acuerdo a sus características tecno-decorativas a "ojo desnudo" (Orton et al. 1997), a los diversos Componentes Morfoestilísticos configurados para la Tambería.

En relación con los Estilos reconocemos que Sanagasta/ Angualasto es el mayoritario con un $73 \%$ de la muestra ( $\mathrm{N}=7290)$; seguido por el Inca Local con un 12\% ( $\mathrm{N}=1208)$; Aguada 6\% ( $\mathrm{N}=604)$ y Sanagasta Pasta Compacta 1\% $(\mathrm{N}=102)$, ambos Estilos muchas veces difícil de distinguir por su similitud y alta fragmentación, y Diaguita Chileno Inca 1\% ( $\mathrm{N}=98)$. El porcentaje restante, 7\% ( $\mathrm{N}=772)$, lo conforman los Componentes Gris Inciso y Negro Engobado del Estilo Santa Clara, modalidades tecnológicas asignadas a tiempos coloniales (siglos XVII y XVIII) (Figura 2). La profundización del conocimiento sobre los diferentes conjuntos alfareros se practicó de acuerdo a un conjunto de herramientas analíticas:

1. Análisis convencionales: de pasta (submacroscópicos, mediante lupa binocular KYOWA OPTICAL SDZ-PL, con objetivos hasta 40X) -textura, color, constitución y cavidades- ( $\mathrm{N}=4200$ tiestos); de técnicas de manufactura; de formas mediante remontajes de partes diagnósticas (bordes, bases, cuerpos y asas), de decoración (tratamientos e identificación de motivos) y de cocción (color, textura y núcleos de cocción) (Cremonte 1990-1991; Munsell Soil Color Charts 1994 y otros).

2. Análisis petrográfico de láminas delgadas cerámicas ( $\mathrm{N}=117)$ : identificación, cuantificación -300 puntos por corte cerámico- y caracterización de antiplásticos y de matriz de pasta (Courtois 1976; Middelton et al. 1985). La observación realizó mediante el manejo de un microscopio petrográfico OLYMPUS BX51.

\section{Resultados de los estudios composicionales de pastas cerámicas}

Las pastas son mayormente de tonalidad naranja/rojiza 
(7.5YR 5/8) y marrón/grisáceo (10YR 6/2), y en menor medida gris (10YR 5/1), aunque dentro de cada grupo de tonalidad señalada existen variaciones cromáticas más claras y oscuras. Poseen textura compacta/porosa y granulometría media y gruesa. La composición de pastas a nivel general incluye cuarzos (22\%); feldespatos (6\%); minerales opacos (8\%); biotita (8\%); muscovita $(9 \%)$; anfíboles $(2 \%)$; piroxenos (4\%); fragmentos de rocas plutónicas (3\%); volcánicas (12\%); sedimentarias (4\%) y metamórficas (2\%).

Ahora bien, advertimos particularidades composicionales de acuerdo a los Estilos Tecnológicos: las cerámicas Sanagasta/Angualasto se destacan por poseer escaso tiesto molido y abundantes inclusiones arcillosas, con valores de alrededor del 20\%; las Aguada y Sanagasta Pasta Compacta presentan pastas muy compactas, con una casi nula presencia de agregados antiplásticos como cuarzos, feldespatos y fragmentos de roca volcánica, no superando en conjunto el 5\%; los Componentes del Estilo Inca Local (Negro sobre Rojo y Rojo Pulido y Engobe Marrón Pulido) muestran una diferencia entre ellos, dado que el primero posee similitud composicional con las piezas Sanagasta, excepto el agregado de tiesto molido e inclusiones arcillosas; y el segundo Componente se constituye de abundante vidrio volcánico -fragmentos pumíceos-, superando el 30\% dentro de sus pastas. La cerámica Diaguita Chileno Inca se distingue por presentar altas cantidades de minerales opacos y rocas volcánicas, exhibiendo alrededor de un 15\% en cada caso. Finalmente, llama la atención los Componentes Negro Engobado y Gris Inciso del Estilo Santa Clara, dado que el primero posee una composición muy similar al registro cerámico Sanagasta/Angualasto aunque sin la presencia de tiesto molido e inclusiones arcillosas, mientras que el segundo se diferencia ampliamente de la muestra, al exhibir abundante carbón vegetal como inclusión antiplástica, con valores de alrededor del $15 \%$.

Los minerales en el registro general se advierten anhedrales, y los restantes constituyentes fundamentalmente sub redondeados/esféricos y sub prismáticas, aunque los tiestos molidos angulosos/esféricos. El tamaño de antiplásticos global (tanto los naturales como aquellos agregados por los alfareros) es entre 0,03 $\mathrm{mm}$ y 2,5 $\mathrm{mm}$-promediando en 0,3 $\mathrm{mm}-$, aunque las pastas Sanagasta/Angualasto ostentan tamaños mayores. La distribución es pobre y equilibrada, la orientación es aleatoria y la densidad entre el 10\% y 20\%, no obstante, las pastas Sanagasta Pasta Compacta y Aguada poseen una densidad menor (5\%). Las cavidades son densas (20\%), con conexión parcial, distribución pobre y equilibrada, formas redondas y alargadas, y un tamaño entre 0,3 mm y $3 \mathrm{~mm}$. No existe una diferenciación marcada en el tratamiento de pastas según la morfología dentro de cada Estilo, las variaciones se reflejan en un tamaño mayor de inclusiones en piezas cerradas de gran porte como ollas y en una mayor densidad de antiplásticos en las bases y asas. Tampoco existe una variación entre recipientes decorados o no decorados.
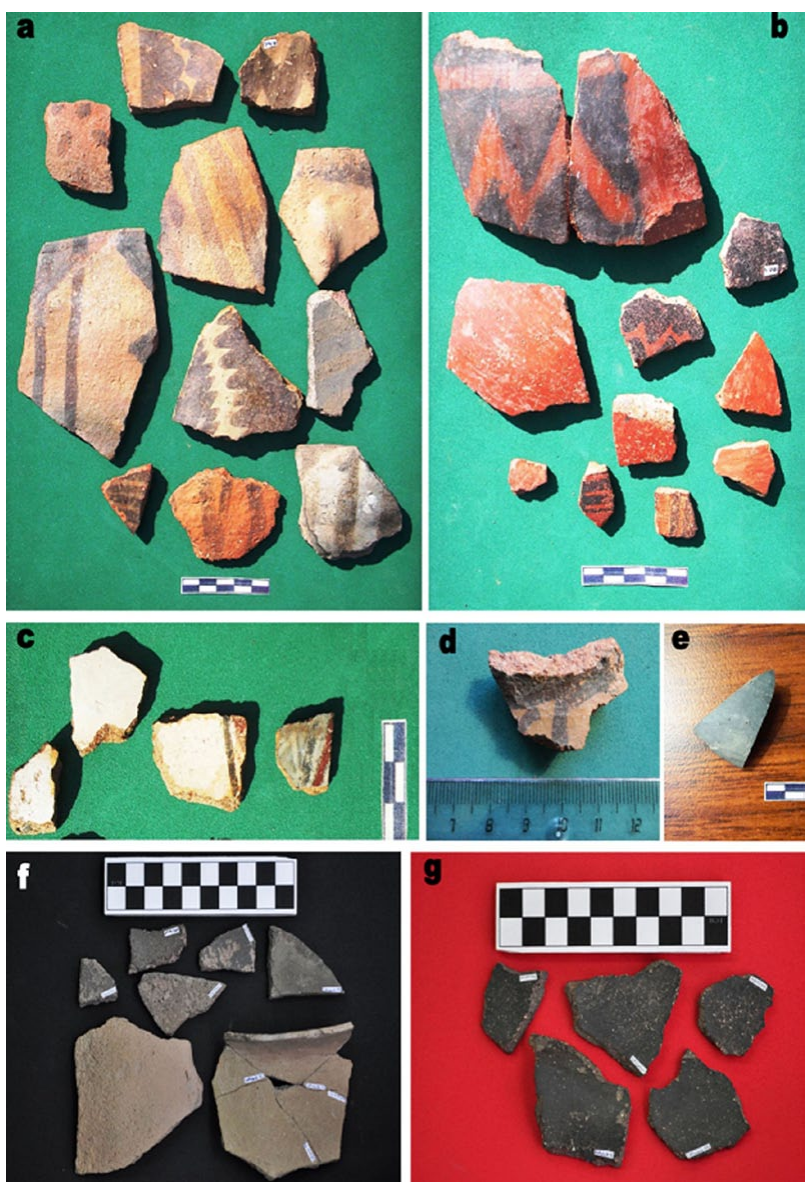

Figura 2. Estilos tecnológicos cerámicos del valle de Guandacol.

Figure 2. Ceramic technological styles of the Guandacol valley.

\section{Resultados de los estudios de técnicas de manufactura y formas cerámicas}

Se observa una homogeneidad general en la aplicación de las técnicas primarias para elaborar las diferentes vasijas, manifestado en la utilización de la técnica de rodeteado, además del modelado y estiramiento de masa. Si bien se advierte la primera técnica en las alfarerías de los Estilos Sanagasta/Angualasto, Inca Local y Sanagasta Pasta Compacta, y el modelado en las piezas Aguada y Santa Clara, esto no es excluyente, dado que en muchos casos las cerámicas fueron levantadas con las restantes técnicas, sobre todo en el Estilo Sanagasta/Angualasto. Asimismo, se observan vasijas con la combinación de técnicas, sobre todo en las de gran porte, para la elaboración de cada parte (modelado y estiramiento de masa para bases y rodeteado para cuerpo y borde).

Además, hay uniformidad en el tipo de técnicas secundarias con una preeminencia del alisado (a veces junto al cepillado), aunque no en el modo, dado que las aplicaciones denotan irregularidad dejando zonas del cuerpo sin un completo tratamiento superficial, particularmente en cerámicas Sanagasta/Angualasto.

En cuanto a las formas pudimos caracterizar al menos cuatro categorías (tinajas, ollas, cuencos y platos), dentro 
de las cuales existe cierta variabilidad. La mayor parte del registro no se pudo discriminar en ninguna de estas agrupaciones. Hallamos formas globulares, con perfiles continuos, sin puntos de inflexión más que para las zonas de unión entre el cuerpo y las bases, e inflexiones suaves entre el cuerpo y los cuellos, bordes evertidos e invertidos con labios convexos, paredes gruesas, bases meniscoconvexas y bicóncavas y asas remachadas y en mamelón. Las ollas y tinajas muestran diámetros de boca entre 40 y $20 \mathrm{~cm}$, y de base entre 13 y $8 \mathrm{~cm}$; los cuencos diámetros de boca entre 45 y $16 \mathrm{~cm}$, y de base entre 10 y $5 \mathrm{~cm}$; los platos diámetro de boca entre 20 y $10 \mathrm{~cm}$, y de bases entre 7 y $11 \mathrm{~cm}$. En cuanto a los Estilos, la mayor variabilidad se exhibe dentro de la alfarería Sanagasta/Angualasto. Las piezas Aguada y Sanagasta Pasta Compacta están representadas por vasijas abiertas (cuencos), al igual que las Diaguita Chileno y Santa Clara. La cerámica Inca Local está constituida por piezas abiertas (cuencos, platos), cerradas (posible aríbalos y jarras) e indeterminadas.

\section{Resultados de los estudios de decoración cerámica}

Existe una regularidad y recurrencia en las elecciones de las técnicas decorativas dentro de cada uno de los Estilos Tecnológicos. El tratamiento de acabado de superficie mayoritario en las piezas Sanagasta/Angualasto es el pintado; en las Santa Clara el engobado/pulido y el inciso; y en los restantes Estilos el engobado/pintado/pulido y engobado/pulido.

La mayor parte de estos tratamientos se efectuaron en las superficies externas de las piezas, y principalmente en cuencos o vasijas abiertas. En cuanto a los motivos decorativos, se hallan bandas (46\%); motivos en $\mathrm{V}(2 \%)$; bandas zig-zag (8\%); puntos (21\%); triángulos (7\%); círculos (10\%); rombos (2\%); cuadrados (1\%) y motivos en $X(1 \%)$. Las pinturas son normalmente negras, aunque también hay roja; mientras que los engobes y baños son de acuerdo a cada uno de los Estilos (ver Tabla 1).

\section{Resultados de los tratamientos de cocción cerámica}

Del total de tiestos, la mitad no presentan cambios en su coloración, mostrando una regularidad monocromática en toda la secuencia desde el núcleo hasta la superficie, la mayoría de ellas naranjas/rojizas. Considerando las cerámicas naranjas/rojizas y marrones como cocciones en atmósfera oxidante, y las grises en atmósfera reductora, determinamos entonces que casi la mitad del registro posee una Oxidación completa y regular en el proceso de cocción; mientras que solo un 1,5\% una Reducción completa y regular. El resto exhibe variabilidad cromática, advirtiendo cocciones en atmósfera incompletas, sobre todo en recipientes con un grosor importante entre 1,5 $\mathrm{cm}$ y $3 \mathrm{~cm}$. El Sanagasta/Angualasto es exclusivamente el que presenta esta irregularidad, la cual está marcada por oxidaciones con márgenes de núcleo difuso y recto. La síntesis de la caracterización de Componentes Morfoestilísticos se puede observar en la Tabla 1.

\section{Discusión y consideraciones finales}

En base a estas aproximaciones comparativas entre los Estilos cerámicos de Guandacol, consideramos que en el área de estudio entre los siglos XIII y XVIII, habría existido una recurrencia en ciertas prácticas de manufactura dentro de la cadena operativa de producción alfarera. Esto se manifiesta fundamentalmente en la composición de pastas, las técnicas primarias y secundarias de manufactura y los tratamientos de cocción cerámica.

Desde el punto de vista composicional, rescatamos la similitud de la alfarería Sanagasta/Angualasto con los Componentes Negro sobre Rojo y Rojo Pulido (Estilo Inca Local) y el Negro Engobado cuya cronología se ajusta a tiempos coloniales (siglos XVII y XVIII). Algo similar ocurre con las cerámicas Aguada y Sanagasta Pasta Compacta, Estilos que muestran una cierta semejanza mineralógica y petrográfica. Esto sugeriría posiblemente un aprovisionamiento de materias primas locales durante un considerable lapso cronológico en Guandacol, probablemente desde momentos del periodo de Integración Regional hasta la época colonial. Asimismo, consideramos que la presencia de tiesto molido en las pastas Sanagasta/Angualasto no solo respondería a factores de índole tecnológico (mejora de las condiciones durante la cocción alfarera), sino también a prácticas tradicionales de manufactura de larga tradición en el NOA (Cremonte y Solís 1998; De la Fuente 2011). De cualquier manera, esto no implica cambios tecnológicos durante este amplio rango temporal, manifestado en el tratamiento de pastas, baja densidad de inclusiones antiplásticas en pastas Aguada y alta en los restantes Estilos.

Las manifestaciones tecnológicas que rompen con la homogeneidad composicional del registro general son los Estilos Diaguita Chileno Inca y los Componentes Engobe Marrón Pulido (Estilo Inca Local) y Gris Inciso (Estilo Santa Clara), este último correspondiente a momentos coloniales. Los dos primeros, con muy bajo porcentaje en el área, tendrían probablemente un origen alóctono, y su presencia respondería a la dinámica de la ocupación del Estado Inca en la región (Bárcena 2010). El Gris Inciso también representa un "quiebre" entre las manifestaciones alfareras del valle, al destacarse por exhibir abundante carbón vegetal. Por el momento no tenemos noción de alfarería con esta particularidad en la región u en otras, y si bien su hallazgo en Guandacol hasta ahora es escaso, no se descarta su presencia en áreas próximas. Desde el punto de vista técnico, estas inclusiones podrían tener su origen en materia orgánica utilizada como antiplástico, o quizás en depósitos carboníferos reconocidos en el área (Furque 1963). Asimismo, muy probablemente las cerámicas hayan sido cocinadas en atmósfera oxidante para conservar su estructura. En estudios futuros se profundizará sobre esta particular alfarería.

En relación con el levantado de recipiente observamos una recurrencia en la elección de las técnicas primarias, 


\begin{tabular}{|c|c|c|c|c|c|}
\hline \multicolumn{6}{|c|}{ COMPONENTES MORFOESTILÍSTICOS CERÁMICOS DEL VALLE DE GUANDACOL } \\
\hline \multirow{2}{*}{$\begin{array}{l}\text { Componentes } \\
\text { Morfo } \\
\text { estilísticos }\end{array}$} & \multicolumn{2}{|r|}{ Pastas } & \multirow{2}{*}{$\begin{array}{l}\text { Técnicas de levantado. } \\
\text { Morfologías aproximadas }\end{array}$} & \multirow[b]{2}{*}{ Decoración } & \multirow{2}{*}{$\begin{array}{c}\text { Estilo } \\
\text { Tecnológico }\end{array}$} \\
\hline & $\begin{array}{l}\text { Color aparente y textura. } \\
\text { Atmósfera de cocción }\end{array}$ & $\begin{array}{c}\text { Composición principal y } \\
\text { características de antiplásticos }\end{array}$ & & & \\
\hline ALISADO & $\begin{array}{l}\text { Naranja/Marrón/Gris. } \\
\text { Textura porosa. Atmósfera } \\
\text { de cocción oxidante. }\end{array}$ & $\begin{array}{l}\text { Rocas (ígneas, sedimentarias y } \\
\text { metamórficas), cuarzo, feldespato, } \\
\text { mica, tiesto molido e inclusiones } \\
\text { arcillosas. Tamaño medio. Distr. } \\
\text { Equilibrada. Densidad } 10 \% \text {. } \\
\text { Esfericidad sub/redondeada. IA\% 7\%- } \\
15 \% \text {. }\end{array}$ & $\begin{array}{l}\text { Rodeteado, modelado y } \\
\text { estiramiento de masa. Cuencos } \\
\text { pequeños, medianos y } \\
\text { grandes; ollas globulares y } \\
\text { subglobulares pequeñas, } \\
\text { medianas y grandes. }\end{array}$ & & \\
\hline $\begin{array}{l}\text { ALISADO } \\
\text { TOSCO }\end{array}$ & $\begin{array}{l}\text { Naranja/Marrón/Gris. } \\
\text { Textura porosa. Atmósfera } \\
\text { de cocción oxidante. }\end{array}$ & $\begin{array}{l}\text { Rocas (igneas, sedimentarias y } \\
\text { metamórficas), cuarzo, mica, } \\
\text { minerales opacos, tiesto molido e } \\
\text { inclusiones arcillosas. Tamaño grande } \\
\text { y medio. Distr. Pobre. Densidad } 10 \% \text {. } \\
\text { Esfericidad redondeada/muy } \\
\text { redondeada. IA\% } 11 \%-17 \% \text {. }\end{array}$ & $\begin{array}{l}\text { Rodeteado, modelado y } \\
\text { estiramiento de masa. Cuencos } \\
\text { grandes; ollas globulares } \\
\text { grandes y muy grandes; } \\
\text { tinajas. }\end{array}$ & & \\
\hline PINTADO & $\begin{array}{l}\text { Naranja/Marrón/Gris. } \\
\text { Textura porosa. Atmósfera } \\
\text { de cocción oxidante. }\end{array}$ & $\begin{array}{l}\text { Rocas (igneas, sedimentarias y } \\
\text { metamórficas), cuarzo, feldespato, } \\
\text { mica, tiesto molido e inclusiones } \\
\text { arcillosas. Tamaño fino, medio y } \\
\text { grande. Distr. equilibrada y pobre. } \\
\text { Esfericidad sub/redondeada. IA\% 7\%- } \\
15 \% \text {. }\end{array}$ & $\begin{array}{l}\text { Rodeteado, ahuecamiento y } \\
\text { estiramiento de masa. Cuencos } \\
\text { o pucos pequeños, medianos y } \\
\text { grandes; ollas globulares y } \\
\text { subglobulares pequeñas, } \\
\text { medianas y grandes. }\end{array}$ & $\begin{array}{l}\text { Tratamiento en pintura negra } \\
\text { (en ocasiones osbre baño } \\
\text { blanco). Motivos: bandas, } \\
\text { serpenteados, ondas, rombos, } \\
\text { triángulos, rombos y bandas } \\
\text { con puntos, escalonados, } \\
\text { dentados, volutas. }\end{array}$ & $\begin{array}{l}\text { SANAGASTA } \\
\text { ANGUALASTO }\end{array}$ \\
\hline $\begin{array}{l}\text { PULIDO Y } \\
\text { PINTADO } \\
\text { PULIDO }\end{array}$ & $\begin{array}{l}\text { Naranja/Marrón Textura } \\
\text { compacta-porosa }\end{array}$ & $\begin{array}{l}\text { Rocas (ígneas, sedimentarias y } \\
\text { metamórficas), cuarzo, feldespato y } \\
\text { mica. Tamaño medio y fino. Distr. } \\
\text { Equilibrada. Densidad 20\%. } \\
\text { Esfericidad sub/redondeada. IA\% 9\%- } \\
13 \% \text {. }\end{array}$ & $\begin{array}{l}\text { Rodeteado, modelado y } \\
\text { estiramiento de masa. Cuencos } \\
\text { o pucos pequeños y medianos; } \\
\text { ollas pequeñas. }\end{array}$ & $\begin{array}{l}\text { Tratamiento en pintura negra y } \\
\text { posteriormente un pulido. } \\
\text { Motivos: bandas, reticulados, } \\
\text { ganchos, peines, escalonados. }\end{array}$ & \\
\hline EXCISO & $\begin{array}{l}\text { Naranja/Marrón/Gris. } \\
\text { Textura porosa. Atmósfera } \\
\text { de cocción oxidante. }\end{array}$ & $\begin{array}{l}\text { Rocas (ígneas, sedimentarias y } \\
\text { metamórficas), cuarzo y feldespato. } \\
\text { Tamaño medio. Distr. Equilibrada. } \\
\text { Densidad 10\%. Esfericidad } \\
\text { sub/redondeada. IA\% } 8 \%-10 \% .\end{array}$ & $\begin{array}{l}\text { Rodeteado. Ollas pequeñas y } \\
\text { medianas. }\end{array}$ & $\begin{array}{l}\text { Tratamiento en excisiones. } \\
\text { Motivos: bandas. }\end{array}$ & \\
\hline PASTILLAJE & $\begin{array}{l}\text { Naranja/Marrón/Gris. } \\
\text { Textura porosa. Atmósfera } \\
\text { de cocción oxidante. }\end{array}$ & $\begin{array}{l}\text { Rocas (ígneas, sedimentarias y } \\
\text { metamórficas), cuarzo, mica, tiesto } \\
\text { molido e inclusiones arcillosas. } \\
\text { Tamaño medio. Distr. Equilibrada. } \\
\text { Densidad } 10 \% \text {. Esfericidad } \\
\text { sub/redondeada. IA\% } 8 \%-10 \% \text {. }\end{array}$ & $\begin{array}{l}\text { Rodeteado y modelado. Ollas } \\
\text { pequeñas y medianas. }\end{array}$ & $\begin{array}{l}\text { Tratamiento pastillaje o } \\
\text { aplicación de arcilla. Motivos: } \\
\text { bandas rectas y en zig-zag. }\end{array}$ & \\
\hline $\begin{array}{l}\text { NEGRO SOBRE } \\
\text { ROJO Y ROJO } \\
\text { PULIDO }\end{array}$ & $\begin{array}{l}\text { Naranja. Textura } \\
\text { compacta-porosa. } \\
\text { Atmósfera de cocción } \\
\text { oxidante. }\end{array}$ & $\begin{array}{l}\text { Rocas (volcánicas y sedimentarias), } \\
\text { cuarzo, feldespato y mica. Tamaño } \\
\text { fino. Distr. Buena. Densidad 20\%. } \\
\text { Esfericidad angulosa. IA\% } 11 \%-14 \% \text {. }\end{array}$ & $\begin{array}{l}\text { Rodeteado, modelado y } \\
\text { estiramiento de masa. Cuencos } \\
\text { o pucos y platos pequeños; } \\
\text { posibles aribalos o aribaloides; } \\
\text { jarras. }\end{array}$ & $\begin{array}{l}\text { Tratamiento en pintura negra } \\
\text { sobre engobe rojo y } \\
\text { ocasionalmente negro, y luego } \\
\text { pulido. Motivos: bandas, } \\
\text { reticulados, triángulos, ondas, } \\
\text { volutas dobles, ganchos y } \\
\text { dentados. }\end{array}$ & INCA LOCAL \\
\hline $\begin{array}{l}\text { ENGOBE } \\
\text { MARRÓN } \\
\text { PULIDO }\end{array}$ & $\begin{array}{l}\text { Marrón rojizo Textura } \\
\text { compacta-porosa. } \\
\text { Atmósfera de cocción } \\
\text { oxidante. }\end{array}$ & $\begin{array}{l}\text { Mica, cuarzo, feldespato, rocas } \\
\text { (igneas) y vidrio volcánico. Tamaño } \\
\text { fino. Distr. Buena. Densidad } 20 \% \text {. } \\
\text { Esfericidad angulosa. IA } \% 2 \%-7 \% \text {. }\end{array}$ & $\begin{array}{l}\text { Rodeteado, modelado y } \\
\text { estiramiento de masa. Cuencos } \\
\text { o pucos y platos pequeños. }\end{array}$ & $\begin{array}{l}\text { Tratamiento en engobe marrón } \\
\text { y luego pulido. }\end{array}$ & \\
\hline $\begin{array}{l}\text { MARRÓN } \\
\text { ROJIZO } \\
\text { ENGOBADO }\end{array}$ & $\begin{array}{l}\text { Marrón rojizo. Textura } \\
\text { compacta-porosa. } \\
\text { Atmósfera de cocción } \\
\text { oxidante. }\end{array}$ & $\begin{array}{l}\text { Rocas (ígneas), cuarzo, feldespato y } \\
\text { minerales opacos. Tamaño fino. Distr. } \\
\text { Buena. Densidad 20\%. Esfericidad } \\
\text { angulosa. IA\% } 7 \%-11 \% \text {. }\end{array}$ & $\begin{array}{l}\text { Rodeteado, modelado y } \\
\text { estiramiento de masa. Cuencos } \\
\text { o pucos y platos pequeños; } \\
\text { ollas pequeñas. }\end{array}$ & $\begin{array}{l}\text { Tratamiento en pintura negra y } \\
\text { roja sobre engobe blanco. } \\
\text { Tramiento en engobe marron. } \\
\text { Luego pulido. Motivos: bandas, } \\
\text { rombos y triángulos. }\end{array}$ & $\begin{array}{l}\text { DIAGUITA } \\
\text { CHILENO INCA }\end{array}$ \\
\hline $\begin{array}{l}\text { ENGOBRE } \\
\text { CREMA }\end{array}$ & $\begin{array}{l}\text { Naranja. Textura } \\
\text { compacta. Atmósfera de } \\
\text { cocción oxidante. }\end{array}$ & $\begin{array}{l}\text { Rocas (volcánicas, sedimentarias), } \\
\text { cuarzo y feldespato. Tamaño muy } \\
\text { fino. Distr. muy pobre. Densidad 10\%. } \\
\text { Esfericidad sub/angulosa. IA\% } 15 \%- \\
17 \% \text {. }\end{array}$ & $\begin{array}{l}\text { Rodeteado, modelado y } \\
\text { estiramiento de masa. Cuencos } \\
\text { o pucos pequeños y medianos; } \\
\text { ollas pequeñas. }\end{array}$ & $\begin{array}{l}\text { Tratamiento en pintura negra, } \\
\text { roja y/o morada sobre engobe } \\
\text { transparente, ante o crema, y } \\
\text { superficie natural, y luego } \\
\text { pulido. Motivos: bandas y } \\
\text { circulos. }\end{array}$ & $\begin{array}{l}\text { SANAGASTA } \\
\text { PASTA } \\
\text { COMPACTA Y/O } \\
\text { AGUADA }\end{array}$ \\
\hline GRIS PULIDO & $\begin{array}{l}\text { Gris. Textura compacta. } \\
\text { Atmósfera de cocción } \\
\text { reductora. }\end{array}$ & $\begin{array}{l}\text { Rocas (ígneas), cuarzo, minerales } \\
\text { opacos, feldespato y mica. Tamaño } \\
\text { fino y muy fino. Distr. Equilibrada. } \\
\text { Densidad 10\%. Esfericidad } \\
\text { sub/angulosa. IA } \% \text { 6\%-13\%. }\end{array}$ & $\begin{array}{l}\text { Rodeteado, modelado y } \\
\text { estiramiento de masa. Cuencos } \\
\text { o pucos y platos pequeños. }\end{array}$ & $\begin{array}{l}\text { Tratamiento pulido sobre } \\
\text { superficie natural o sobre } \\
\text { engobe/barniz (trasparente), y } \\
\text { luego pulido. También se } \\
\text { presenta con incisiones en } \\
\text { ocasiones. Motivos: círculos, } \\
\text { líneas finas. }\end{array}$ & $\begin{array}{l}\text { AGUADA/CIÉNA } \\
\text { GAJPUNTA DEL } \\
\text { BARRO? }\end{array}$ \\
\hline GRIS INCISO & $\begin{array}{l}\text { Gris. Textura porosa. } \\
\text { Atmósfera de cocción } \\
\text { reductora. }\end{array}$ & $\begin{array}{l}\text { Carbón vegetal, cuarzo, feldespato y } \\
\text { rocas (volcánicas y sedimentarias). } \\
\text { Tamaño fino y medio. Distr. } \\
\text { Equilibrada. Densidad 20\%. } \\
\text { Esfericidad sub/redondeada. IA\% 9\%- } \\
\text { 19\%. }\end{array}$ & $\begin{array}{l}\text { Modelado y estiramiento de } \\
\text { masa. Cuencos o pucos y } \\
\text { platos pequeños. }\end{array}$ & $\begin{array}{l}\text { Tratamiento en incisiones } \\
\text { sobre superficie natural. } \\
\text { Motivos: puntos, líneas finas. }\end{array}$ & SANTA CLARA \\
\hline $\begin{array}{l}\text { NEGRO } \\
\text { ENGOBADO }\end{array}$ & $\begin{array}{l}\text { Gris. Textura compacta- } \\
\text { porosa. Atmósfera de } \\
\text { cocción reductora. }\end{array}$ & $\begin{array}{l}\text { Rocas (ígneas, sedimetarias y } \\
\text { metamórficas), cuarzo y feldespato. } \\
\text { Tamaño medio. Distr. Muy pobre. } \\
\text { Densidad 20\%. Esfericidad } \\
\text { sub/redondeada. IA\% } 9 \%-15 \% \text {. }\end{array}$ & $\begin{array}{l}\text { Rodeteado, modelado y } \\
\text { estiramiento de masa. Cuencos } \\
\text { o pucos y platos pequeños. }\end{array}$ & $\begin{array}{l}\text { Tratamiento en engobe negro, } \\
\text { y luego pulido. }\end{array}$ & \\
\hline
\end{tabular}

Tabla 1. Características generales de los componentes morfoestlísticos cerámicos del valle de Guandacol.

Table 1. General trends of ceramic morpho-stylistics components in the Guandacol valley. 
aunque en cada Estilo predomina una técnica por sobre otras. Sin embargo, el registro se halla muy fragmentado, lo que imposibilita una completa apreciación. En cuanto a las técnicas secundarias, se advierte una homogeneidad en la elección (preeminencia de alisados), aunque no en la aplicación, con más irregularidad dentro de la alfarería Sanagasta/Angualasto. A manera de hipótesis, pensamos que esta situación se debería a una falta de inversión de tiempo en el acabado de las piezas, dada en un contexto de producción condicionado por una alta demanda de bienes debido al aumento progresivo de población durante el Tardío en el valle (Carosio 2015).

En cuanto a las formas, destacamos que son bastante similares en los distintos Estilos, aunque las de gran porte se corresponden a las Sanagasta/Angualasto. Respecto a la decoración, es un elemento que permite una discriminación de los Estilos, y en el caso de la alfarería Sanagasta/Angualasto hay una predilección de utilizar como acabado la pintura mientras que, en el Inca local, Aguada y Sanagasta Pasta Compacta, se destacan los engobes en diferentes gamas. Las incisiones son preferentes en el Componente Gris Inciso y observada para algunas piezas del Tardío. Esto reflejaría ciertos cambios tecnológicos entre los productores a lo largo del proceso de ocupación del valle.

Finalmente, en relación con las cocciones, la mayoría de las vasijas fueron cocinadas en atmósfera oxidante, demostrando una prolongación en el tiempo de las modalidades de cocción. La ruptura con el registro mayoritario la marcan los Componentes Gris Pulido, Gris Inciso y Negro Engobado, los cuales tienen cocciones en atmósfera reductora. De cualquier manera, es conocido que las tonalidades de pasta pueden obtenerse de diferentes formas en una cochura y al no poseer restos de estructuras de combustión es difícil determinar las características de esta fase operativa.

Todos estos resultados deberán ampliarse y contrastarse mediante el aumento de muestras cerámicas, sedimentos arcillosos y arenosos locales, excavaciones en nuevos sitios arqueológicos y fechados en la región. La interrelación de diferentes líneas de investigación podrá contribuir a un mejor acercamiento a las características de la tecnología cerámica en el área, los modos de producción y los procesos socio-históricos inherentes durante los tiempos prehistóricos e históricos.

\section{Referencias bibliográficas}

Bárcena, J. R. 2010. Investigaciones arqueológicas en la "Tambería de Guandacol" (Departamento Felipe Varela, Provincia de La Rioja). Bárcena J. R. (Editor.): en Aportes de las IV Jornadas Arqueológicas Cuyanas, $N^{\circ}$ 4, XAMA Series Monográficas 2; 121-181. INCIHUSA-CONICET. Mendoza, Argentina.

Boman, E. 1927-1932. Estudios arqueológicos riojanos. Anales del Museo Nacional de Historia Natural, 35, 72, Antropología. Bs. As
Callegari A. \& M. Gonaldi. 2006. Procesos diferenciados entre las sociedades Aguada (período de Integración) que se desarrollaron en el oeste y centro de la Provincia de La Rioja (centro del valle de Vinchina y valle de Antinaco- Dto. de Famatina). Chungara 38 (2): 197-210.

Callegari, A. \& M. Gonaldi. 2007-2008. Guandacol. Estructuras arquitectónicas tardías del sudoeste de la provincia de La Rioja. Arqueología 14: 173-187.

Carosio, S. 2015. Investigaciones ceramológicas en el oeste de la provincia de La Rioja: La Tambería de Guandacol y el periodo de los Desarrollos Regionales (1000-1470 AD). Tesis de doctorado inédita. FFYH, UNC.

Carosio, S., L. Iniesta \& J. R. Bárcena. 2011. Análisis ceramológicos de la Tambería de Guandacol (Dpto. Felipe Varela, provincia de La Rioja). Avances para el conocimiento de las prácticas de manufactura. Comechingonia Virtual, Vol. V, º2:98-127.

Carosio, S., Martínez, A. \& R. Bárcena. 2012. Pastas cerámicas de la Tambería de Guandacol, Dpto. Felipe Varela, provincia de La Rioja (Argentina): estudio mineralógico y petrográfico. XIII Congreso Geológico Chileno, T 10-Geopatrimonio: 905-907.

Cobas, M. I \& M. P. Prieto 1998. Regularidades espaciales en la cultura material: la cerámica de la edad del bronce y la edad del hierro en Galicia. Gallaecia 17: 151-175.

Courtois, L. 1976. Examen au microscope pétrographique des céramiques archéologiques. Notes et Monographies Techniques $N^{\circ}$ 8. CNRS. Paris.

Cremonte, M. B. 1990-1991. Análisis de Muestras de Cerámicas de la Quebrada de Humahuaca. Avances en Arqueología 1: 7-42.

Cremonte, M. B. \& N. Solis. 1998. La cerámica del Pucara de Volcán: Variaciones locales y evidencias de interacción. Los Desarrollos Locales y sus territorios. M. B. Cremonte Comp. En Arqueología del NOA y sur de Bolivia, pp. 155-196. UNJu.

De La Fuente, N. 1973. El yacimiento arqueológico de Guandacol, provincia de La Rioja. Revista del Instituto de Antropología, IV: 151-167.

De La Fuente, G. 2011. Urns, Bowls, and Ollas: Pottery-Making Practices and Technical Identity in the Southern Andes During the Late Period (ca. A.D. 900-A.D. 1450) (Catamarca, Northwestern Argentine Region, Argentina). Latin Am. Antiquity 22, 2: 224-252.

Furque, G. 1963. Descripción de la Hoja Geológica 17b, Guandacol - Provincia de La Rioja. Boletín de la Dirección Nacional de Geología y Minería. Buenos Aires No 92: 1-104.

Iniesta, M. L. \& J. R. Bárcena. 2014. Investigaciones arqueológicas sobre las sociedades tardías del Valle de Guandacol (departamento Felipe Varela, oeste de La Rioja): Espacio, estilos tecnológicos cerámicos y cronología. Arqueología 20: 61-82.

Lemonnier, P. 1992. Elements for Anthropology of Technology. Anthropological Papers $N^{\circ}$ 88. Museum of Anthropology, University of Michigan.Ann Arbor.

Middleton, A. P., Freestone I. C. \& M. N. Leese. 1985. Textural analysis of ceramic thin sections: evaluation of grain sampling procedures. Archaeometry 21, 1: 64-14.

Munsell Soil Color Charts. 1994. Munsell Color. Macbeth Division of Kollmorgen Instruments Corporation, New Windsor, NY.

Orton, C., Tyers, P. \& A. Vince. 1997. La cerámica en arqueología. Crítica. Barcelona.

Rice, P. 1987. Pottery Analysis. A sourcebook. University of Chicago Press. Chicago. 